\title{
ALTE — APPARENT LIFE-THREATENING EVENT IN CHILDREN
}

\section{Grzegorz Bujok}

Hospital Emergency Department, Chorzów Centre of Paediatrics and Oncology

\begin{abstract}
The data available in the literature associated with apparent life-threatening event (ALTE) in young children, a syndrome rarely diagnosed in Polish emergency departments, are discussed in this paper. The importance of properly conducted interviews, emotional aspects and their practical role in the early management of the case at the site of the event, proposed diagnostic criteria, as well as suggestions for the diagnostic process and decisions related to follow-up are presented.
\end{abstract}

KEY WORDS: children, life threatening, SIDS, respiration

Disaster Emerg Med J 2017; 2(2): 94-97

\section{INTRODUCTION}

Although apparent life-threatening event (ALTE) is a diagnostic term most commonly used in English-speaking countries, considering its clinical presentation it may be presumed that its incidence is high in all geographical areas. ALTE is a subjective term, which results from a specific perception of a certain situation by a person providing medical aid. The clinical presentation of ALTE includes one or more symptoms such as apnoea, skin colour changes, change in muscle tone, choking or gagging that persist for a shorter or longer time [1-3].

Many authors emphasize that to diagnose ALTE the symptoms observed in the child should be considered alarming by the caregiver who witnessed the event. Nevertheless, ALTE is not a diagnosis but a group of symptoms, usually very non-specific. It typically occurs in children, with a peak incidence at 1 to 8 weeks of life. Considering the fact that episodes of ALTE recur only in $10 \%$ of patients, it can be suspected that they manifest disorders of the period of adaptation to postnatal life $[2,4,5]$.

There are controversial similarities between the clinical manifestations of ALTE and sudden infant death syndrome (SIDS). However, many statistical data clearly indicate the lack of association between ALTE and SIDS. Results of epidemiological studies are also difficult to evaluate. This is due to various reasons, particularly differences in the definitions and diagnostic criteria adopted by various authors, or subjective, usually ex post, descriptions of events made by the caregivers or paramedics $[4,6,7]$.

\section{GENERAL ASPECTS OF DIAGNOSTIC PROCEDURE AT ED}

The diagnosis of ALTE, particularly in the pre-hospital period, is difficult and requires both high clinical expertise, experience, and the ability of medical staff to control their own emotions and those of other people. Incorrect baseline information, which can easily be given in stressful circumstances, generates errors at further steps of patient management. Therefore, most authors emphasize the role of efficiently gathered information from a targeted medical interview, which should consider the particulars of the current episode: the duration of the necessary resuscitation activities and their estimated scope, any potential link between the incident and feeding, sleeping, crying, vomiting or choking; symptoms associated 
with breathing or generally understood - even by caregivers - respiratory function; a history of SIDS, heart defects, seizures, metabolic diseases; prematurity; a history of episodes of apnoea; early difficulties in the coordination of breathing and feeding; factors responsible for central or obstructive apnoea. Episodic alterations in the generally defined mental status of the child observed in the past may also be important $[2,4,6,8]$.

Due to the nature of ALTE the predictive value of risk factors is relative. Major risk factors include the functional and structural immaturity of systems regulating homeostasis, usually due to preterm birth; age under 10 weeks; infection with RSV; presence of gastroesophageal reflux disease; recently received anaesthesia; and episodes of pallor and cyanosis during feeding $[3,5,7]$.

A combination of symptoms described as ALTE as a result of further diagnostic procedures, carried out both in the ED and in other departments, is considered idiopathic in more than $50 \%$ of cases. Fewer patients are diagnosed with GERD (gastroesophageal reflux disease), seizures and respiratory tract infections. From a clinical point of view, it is important that in a large percentage of cases ALTE is confused with mild physiological disorders such as periodic breathing and episodes of vomiting. In many cases, ALTE is misdiagnosed due to its clinical similarities with generally mild medical conditions such as periodic breathing and a sudden onset of vomiting. Pertussis, certain injuries and poisoning, as well as electrolyte disorders and hypoglycaemia may also produce clinical symptoms similar to ALTE. The rarest causes of these symptoms are cardiac arrhythmia, anaemia, episodes of shortness of breath (affective dyspnoea) and metabolic diseases $[1,2,5,7,9]$.

\section{DIAGNOSTIC PROCEDURE IN CHILDREN WITH A HISTORY OF ALTE}

As mentioned before, information from the medical interview is of crucial importance. Data obtained from the interview and the results of a physical examination should guide practitioners towards the selection of diagnostic tests in order to narrow down as much as possible the list of diseases considered in the differential diagnosis. This helps to save a lot of time, which significantly improves patient safety and reduces the costs of further management.

Basic tests mentioned in the American literature include complete blood count, a panel of 10 bio- chemical tests, general urine analysis, chest X-ray, as well as a nasal swab for the detection of respiratory syncytial virus (RSV). ECG and MRI of the CNS are indicated as optional tests $[2,3]$.

For the purpose of procedures at ED, as well as the further decision-making process, Mittal and Kaji proposed a list of selected factors which, on one hand, are useful in evaluating threat to life, but also reduce the number of unnecessary admissions to hospital. Decision-making algorithms are created based on a multidimensional statistical analysis of representative populations.

This is particularly complicated in the case of ALTE because of very small study groups and different views on diagnostic procedures $[4,5,9]$.

Mittal analysed a group of 300 infants admitted to one hospital and proposed criteria based on which patients could be discharged home safely without any intervention. The study identified prematurity, abnormal results in the physical examination, colour change to cyanosis, the absence of symptoms of respiratory tract infection, and the absence of choking as predictors for significant intervention. The model had a negative predictive value of $96 \%$ and a specificity value of $70.5 \%$ [5].

Kaji carried out another study on a group of 823 patients and proposed the following variables which would have mandated hospital admission: the need for oxygen therapy; a history of resuscitation; haemodynamic instability; positive results of tests for pertussis and RSV infection; significant data from the interview, such as heart defects; coexisting Down syndrome; a history of intubation; chronic lung diseases with a focus on bronchopulmonary dysplasia and neonatal respiratory distress syndrome; and more than one episode of ALTE/24 hours. This model had a negative predictive value of $96.5 \%$, a sensitivity value of $89 \%$ and a a specificity value of $61.9 \%$ [4].

Practitioners who want to follow these clinical decision rules should remember that the studies by Mittal and Kaji have not been validated. It should also be emphasized that the two above-presented algorithms apply to the diagnosis and management of patients who experienced an episode of ALTE, but are different in qualitative terms. More precisely, Mittal indicates clinical symptoms suggesting no need for intervention, while Kaji proposes criteria necessitating hospital admission. Both of these models can therefore be considered complementary, particularly if they are used in the same patient 
concurrently. The clinical decision rules proposed by Mittal are mainly valuable for their economic aspects, while Kaji emphasizes patient safety regardless of the controversial clinical presentation in a specific child.

Relatively common criteria accepted for the hospitalization of children following an episode of ALTE include as follows: children born before gestational age GA 48; children with a toxic appearance; inflammation or whooping cough associated with apnoea; more than one episode of ALTE in the last 24 hours or multiple episodes; central apnoea persisting for more than 20 seconds; ALTE requiring resuscitation; as well as a family history of SIDS $[4,5,9]$.

Early management in a hospital setting largely depends on the general status of the child. Treatment of stable patients should mainly focus on the major medical problem. However, the available literature does not provide any guidelines based on the principles of EBM to be applied in children without a precise diagnosis. Some suggestions concerning the management of unstable paediatric patients are presented in the Table $1[3,5,9,10]$.

\section{ASSOCIATION BETWEEN ALTE AND SIDS}

Recent reports emphasize the definitional problems associated with various forms of direct threats to life in newborns and infants. This seems important for both purely clinical reasons and medical jurisprudence. Current nomenclature used in relation to the problem being discussed here is presented below $[7,9,10]$.

These include: SUPC — sudden unexpected postnatal collapse, also described as early ALTE; SUEND - sudden unexpected newborn death; eSUDI
- early sudden unexpected death in infancy; SIDS — sudden infant death syndrome, a case of SUDI of unexpected aetiology that may occur between days 7 and 365 of life. These medical problems occur in potentially healthy newborns between 2 hours and 7 days after birth.

Cot death is a frequently used term in this context. In diagnostic terms it is considered as a synonym of sudden infant death syndrome (SIDS), defined as the sudden death of an apparently healthy infant. Cot death is attributed to various causes: congenital serotonin deficiency; recurrent episodes of apnoea; heart defects; and compression of the vertebral artery - especially important when the baby sleeps on the tummy and lifts the head, which results in the compression of the artery and blockage of blood supply to the brain. A history of SIDS in a family may indicate a genetic background of this problem. Another underestimated pathogenic factor for SIDS is bacterial infection, e.g. with Escherichia coli [10-12].

Risk factors completely different from those described in relation to ALTE include as follows: the young age of the mother - under 19 years; a history of multiple miscarriages; placing an infant to sleep on the stomach or the side; SIDS syndrome in siblings; drug abuse; coffee abuse and tobacco smoking in the mother; passive smoking; premature birth; use of a soft pillow; and winter as a season of low temperature and increased incidence of bacterial infection $[4,10,11]$.

\section{CONCLUSIONS}

ALTE and SIDS - regardless of the epidemiological and pathophysiological differences postulated in the literature - pose a direct threat to infants' lives. In

\begin{tabular}{|c|c|c|}
\hline Medications or interventions & Indications & Dosage \\
\hline Glucose & Hypoglycaemia & 5-10 ml/kg 10\% water solution iv \\
\hline $3 \%$ solution of $\mathrm{NaCl}$ & Symptomatic hyponatremia & $3-5 \mathrm{ml} / \mathrm{kg}$ iv \\
\hline $\begin{array}{l}\text { Calcium gluconate } \\
\text { Calcium chloride }\end{array}$ & Hypocalcaemia & $\begin{array}{l}50-100 \mathrm{mg} / \mathrm{kg} \text { calcium gluconate or } \\
20 \mathrm{mg} / \mathrm{kg} \text { calcium chloride }\end{array}$ \\
\hline Cefotaxime & Infection & $50 \mathrm{mg} / \mathrm{kg}$ iv \\
\hline Ampicillin & Infection & $50 \mathrm{mg} / \mathrm{kg}$ iv \\
\hline PRBCS & Anaemia & $10 \mathrm{ml} / \mathrm{kg}$ iv \\
\hline $0.9 \% \mathrm{NaCl}$ & Dehydration, low blood pressure & $20 \mathrm{ml} / \mathrm{kg}$ iv \\
\hline $10 \%$ glucose in $0.25 \% \mathrm{NaCl}$ & Metabolic diseases & $6 \mathrm{ml} / \mathrm{kg} / \mathrm{h} /$ first $10 \mathrm{~kg} \mathrm{bw}$ \\
\hline Endotracheal intubation & Decreased alveolar ventilation or apnoea (more often) & \\
\hline
\end{tabular}


terms of emergency medicine ALTE and SIDS seem to represent subsequent stages of the same process, which, when initiated by one of many pathogenic factors, not precisely identified in the preliminary diagnostics, leads to the impairment or disorders of circulatory, respiratory and nervous system functions.

The problem requires further study, both in the field of basic science and clinical trials. Interpretation of the whole clinical presentation is complicated in terms of epidemiology because of difficulties related to definitions. A solution to this is expected from the next version of ICD, which should help reduce the number of "avoidable deaths" in this sensitive population of paediatric patients.

Conflict of interest: None declared.

\section{REFERENCES}

1. Aminiahidashti H. Infantile Apparent Life-Threatening Events, an Educational Review. Emerg (Tehran). 2015; 3(1): 8-15, indexed in Pubmed: 26512363.

2. Kundra $M$, Duffy $E$, Thomas $R$, et al. Management of an apparent life-threatening event: a survey of emergency physicians practice. Clin Pediatr (Phila). 2012; 51(2): 130-133, doi: 10.1177/0009922811419495, indexed in Pubmed: 21903620.

3. Sarohia M, Platt S. Apparent life-threatening events in children: practical evaluation and management. Pediatr Emerg Med Pract. 2014; 11(4): 1-14; quiz 15, indexed in Pubmed: 24834606.

4. Kaji AH, Claudius I, Santillanes G, et al. Apparent life-threatening event: multicenter prospective cohort study to develop a clinical decision rule for admission to the hospital. Ann Emerg Med. 2013;
61(4): 379-387.e4, doi: 10.1016/j.annemergmed.2012.08.035, indexed in Pubmed: 23026786.

5. Mittal MK, Sun G, Baren JM. A clinical decision rule to identify infants with apparent life-threatening event who can be safely discharged from the emergency department. Pediatr Emerg Care. 2012; 28(7): 599-605, doi: 10.1097/PEC.0b013e31825c5576, indexed in Pubmed: 22743742.

6. Horne RSC, Nixon GM. The role of physiological studies and apnoea monitoring in infants. Paediatr Respir Rev. 2014; 15(4): 312-318, doi: 10.1016/j.prrv.2014.09.007, indexed in Pubmed: 25304428.

7. Martínez Monseny A, Bobillo Pérez S, Martínez Planas A, et al. The role of complementary examinations and home monitoring in patient at risk from apparent life threatening event, apneas and sudden infant death syndrome. An Pediatr (Barc). 2015; 83(2): 104-108, doi: 10.1016/j. anpedi.2014.11.010, indexed in Pubmed: 25801068.

8. Choi HJ, Kim YH. Relationship between the Clinical Characteristics and Intervention Scores of Infants with Apparent Life-threatening Events. J Korean Med Sci. 2015; 30(6): 763-769, doi: 10.3346/ jkms.2015.30.6.763, indexed in Pubmed: 26028930.

9. Koul R, Alshihi $A$, Mani $R$, et al. Eating epilepsy or feeding epilepsy in an infant. Eur J Paediatr Neurol. 2014; 18(3): 409-412, doi: 10.1016/j. ejpn.2013.10.004, indexed in Pubmed: 24238820.

10. Fuger $M$, Merdariu D, Maurey $H$, et al. Relevance of electroencephalography in infants presenting to an emergency department who have had an apparent life-threatening event. Arch Pediatr. 2014; 21(11): 1206-1212, doi: 10.1016/j.arcped.2014.08.007, indexed in Pubmed: 25282457.

11. Elias MD, Iyer VR, Cohen MS. Prevalence of electrocardiogram use in infants with apparent life-threatening events: a multicenter database study. Pediatr Emerg Care. 2014; 30(4): 236-239, doi: 10.1097/ PEC.0000000000000103, indexed in Pubmed: 24651217.

12. Moltedo JM, Benjamín MN, Olmedo J, et al. An apparent life threatening secondary to long Qt syndrome. Medicina (B Aires). 2013; 73(2): 153-154, indexed in Pubmed: 23570766. 